frittered away on needless duplication. And there is a case for a continuing reassessment of the prospects for fusion reactors. In the long run, these must provide the best hope of a continuing supply of energy. After the first few heady moments in the 1960s, the prospect of controlled fusion has seemed-as it must-a distant goal. But success in half a century would be a comfortable outcome of the work now under way-an interval roughly comparable with the time taken to turn Faraday's discoveries in electromagnetism into workable generators of electricity in bulk.

\section{Insuring for Thalidomide}

THE thalidomide disaster in the early 1960 s casts a long shadow, as the debate in the House of Commons this week has shown clearly enough. And nobody will complain that members of all parties have for several weeks been exercised at the long delay which there has been in settling the civil legal suits by means of which the victims of this disaster-parents as well as limbless childrenhave sought compensation from the manufacturers of the drug in Britain, the Distillers Company Ltd. Although monetary compensation is only an inadequate recompense for the damage that has been done, it is obviously intolerable that it should have been so long delayed. And when all the fuss is over, there will be an urgent need to re-examine the principles on which the High Court has forbidden the publication in the Sunday Times of articles which might be held to increase the pressure from the public to see that compensation is as generous as possible. But there is no suggestion that the delays in settling these civil suits could have been avoided, and there is no assurance that with present arrangements for assessing the legal liability of pharmaceutical manufacturers, the consequences of further accidents of this kind will not be equally unpalatable. So is there not a case for a recasting of the arrangements for determining the liability of manufacturers for accidents which they perpetrate?

The issue is important not merely so that justice shall be quickly done but also because there is a danger that the present muddle about compensation is likely to be a powerful restraint on the willingness of pharmaceutical companies to put new drugs on the market. To be sure, when thalidomide was first launched, there was nothing to suggest that it might be teratogenic and no formal procedures-in Britain at least-for screening drugs for such effects. Even now, however, there remains a chance that some new product might turn out to be capable of causing damage as widespread as that now attributed to thalidomide, for no screening process based on animal experiments can ever be entirely cast-iron. And the risk that some technical innovation will cause unexpected damage is not confined to the pharmaceutical industry. What would happen, and who would be responsible, if there were a latter-day version of the disaster that struck Halifax, Nova Scotia, during the First World War when an ammunition ship in the harbour exploded?

In present circumstances, at least in Britain, most of the technical innovations that might lead to widespread and unexpected damage involve the government, directly or implicitly. Drugs must now be approved before being put on the market. Industrial plants of all kinds cannot be put just where their designers wish, but must satisfy all kinds of planning requirements. So is it proper that, if something should unexpectedly go wrong, the government (as custodian of the public interest) should have its hands quite free? The case of nuclear energy is a good illustration of how governments have formally accepted responsibility as insurers of the last resort, and the International Convention on third-party liability, now ten years old, is a splendid model that might be followed in quite different fields. The notion is that the operators of nuclear plants are responsible for insuring against the costs of accidents up to a certain very large sum of money - $\$ 50$ million-but that governments step in thereafter to carry the larger risks that might well be involved. Especially because, in theory at least, nuclear accidents could have international consequences, this arrangement has some obvious political advantages. But the principle that could usefully be applied elsewhere is that the governments implicity responsible for agreeing that particular technical innovations should go forward will shoulder ultimate responsibility for insurance against accidents of unexpected seriousness, even though those directly responsible for innovations should, alone, take the first substantial slice of responsibility.

\section{Years Ago}

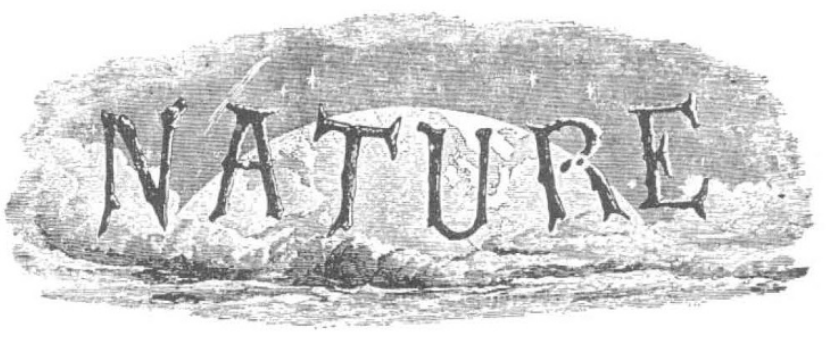

The Great Meteoric Shower

As you will most probably have received from many other correspondents a general description of the magnificent spectacle on last Wednesday evening, I will confine my remarks princi. pally to those observations which bear directly on the most important point at issue, viz., whether this meteor stream can be identified with the well-known comet of Biela. Having searched, during the autumn, on every available occasion for a glimpse at the approaching comet, and the almest unvarying cloudiness of the early morning sky having rendered even the negative value of the observations well-nigh useless, I read with delight the prediction of Dr. Weiss, and felt the greatest interest in its fulfilment.

Immediately I had noticed that 2 meteoric shower was in progress on the evening of the 27th, I directed the two assistants of the observatory, who have had considerable experience in tracing the paths of meteors during the last few years, to devote their whole attention to the accurate determination of the radiant point. In the meantime, with the assistance of three of the students of the philosophy class and of the meteorological assis. tants of the observatory, I noted the rate per minute, the velocity, direction, magnitude, \&c., of the falling bodies.

The Radiant was found to be on the line joining $\gamma$ and $51 \mathrm{An}$ dromedx, and twice as far from $5 \mathrm{I}$ as from $\gamma$. This gives as the R.A., $26^{\circ} 37^{\prime}$, and N. Decl. $43^{\circ} 48^{\prime}$, agreeing very well with the prediction.

The Epoch is somewhat in advance of that predicted; but this cannot be wondered at, as the comet has not been seen since 1852 , and, in three complete revolutions round its orbit, it could scarcely have been expected not to have been subjected to con. siderable unknown perturbation, either from planets whose masses are imperfectly known, or perhaps from some neighbour. ing meteor-stream.

Stonyhurst Observatory, Dec. I

From Nature, 7, 84, December 5, 1872. 